palaeobiological issues underlying the study of ancient marine reptiles. Did fins evolve to legs and back to fins again? And what was more important, homoplasy or homology? Selection or constraint? Unique morphologies or modifications of the old? Marine reptiles are a model system for posing a broad range of questions about the evolution of tetrapods in aquatic environments. We often consider cetaceans or pinnipeds in this light, yet forget that ichthyosaurs were 'dolphinlike' about 190 million years before the first proto-dolphin even thought of going for a swim.

Michael W. Caldwell is in the Department of Biological Sciences, University of Alberta,

Edmonton, Alberta, Canada T6G 2E9.

\section{Axioms for biology}

\section{Foundations of Biophilosophy}

by Martin Mahner and Mario Bunge Springer: 1997. Pp. 423. \$54, £36.50

\section{PaulE.Griffiths}

The logical empiricist consensus that existed in the philosophy of science until the 1960s held that the ideal statement of a scientific theory would be a formal axiom system of the kind found in mathematics. The biologist J. $\mathrm{H}$. Woodger is remembered for his attempts to make biology live up to this ideal. For reasons too complex and varied to explore here, few philosophers of science now try to make scientific theories axiomatic.

It is therefore surprising to find the biologist Martin Mahner and the philosopher Mario Bunge formulating their general account of biology using the logical apparatus of predicate calculus and set theory, complete with axioms, definitions and corollaries. Their aim appears twofold: to ensure consistency between their views on diverse topics and to ensure that their biological views are as tightly constrained as possible by the metaphysics that occupies the first third of their book. This introductory section takes a stand on most of the basic questions of metaphysics and epistemology. Topics covered include basic ontology (the nature of events, properties and things), the interpretation of the probability calculus and the nature of truth and evidence. Philosophers will be frustrated at the speed with which Mahner and Bunge dismiss alternative positions, and biologists should beware of taking their often strongly stated views to represent a philosophical consensus. However, it is hard to see how these problems could be avoided without turning this into a book on metaphysics and epistemology, rather than biology. Bunge has argued at length for his views in many other works.

Perhaps the biggest surprise is that there is no discussion of the reduction of Mendelian to molecular genetics. This is the topic in the philosophy of biology most influenced by the axiomatic method. The original idea of 'theory reduction' was that the axioms of one, formalized theory should be derived logically from those of another, thus showing that nothing is lost when the former is replaced by the latter. This omission is more surprising because the coverage of the book is otherwise excellent.

There are two further surprises in Mahner and Bunge's biophilosophy. First, they reject 'population thinking': evolution is not about ensembles of individuals but about types of organism. They argue that these types, which include species, are in some sense 'natural kinds'. They strongly reject the consensus view, deriving from David L. Hull and Michael Ghiselin, that taxa are ontologically akin to individual objects such as nations rather than to natural kinds such as gold. The second surprise is the authors' radical approach to developmental biology: development is not guided by a genetic program. Instead, Mahner and Bunge call for a synthesis between the 'structuralist' approach to development, which seeks emergent laws of complex biological systems, and the 'constructionist' view that the control of development cannot be localized in one material cause.

Having adopted this radical perspective, Mahner and Bunge attack existing structuralists and constructionists in a manner worthy of Trotskyite splinter politics. The structuralism of Brian Goodwin must be rescued from "holism, (crypto)idealism and subjectivism" by the adoption of Mahner and Bunge's metaphysical scheme. My own advocacy of constructionism with the biologist Russell Gray "must be judged as an utter failure" because of a "severely flawed ontology" which I share with A. N. Whitehead and Hull.

Mahner and Bunge convict most existing biological theorists of basic metaphysical errors, something they hope to avoid through their formal, axiomatic method. For example, Theodosius Dobzhansky characterized evolution as change in the genetic composition of populations owing to "altered interactions with their environment". The authors may be right that it is strictly organisms rather than populations that interact with the environment, but I remain unconvinced that Dobzhansky's slip shows "how easily habits of speech may obfuscate clarity and proper theorising".

This tendency to over-diagnose fundamental metaphysical confusions and to deduce absurd apparent consequences reduces the usefulness of this book as a text for students, despite its admirably wide coverage of the subject. The axiomatic framework and use of logical symbolism will also be unattractive to students, especially those in biology.

Paul E. Griffiths is in the Department of Philosophy, University of Otago, PO Box 56,

Dunedin, New Zealand.
When the rains

\section{come}

\section{Climates of South Asia}

by G. B. Pant and K. Rupa Kumar

Wiley: 1997. Pp. 320. £75, \$130

Julia Slingo

The climate of South Asia is dominated by the monsoon, which returns with remarkable regularity each summer and provides the rainfall needed to sustain more than 60 per cent of the world's population. The vastness of the Asian continent and the unique configuration of the East African Highlands and the Tibetan Plateau mean that the Indian summer monsoon is the most vigorous and influential of all the monsoon circulations. Increasingly, the monsoon is being seen as an important player in the global climate.

It is fortuitous that the first book detailing the climatology of South Asia should be published on the fiftieth anniversary of India's independence. Without the influence of the British Raj and scientists such as Blanford, who in 1886 recognized "the paramount importance of knowledge of distribution of rainfall in space and time", the comprehensive database that provides the core of this book might not have been realized.

The book brings together the vast literature and data resources of India and its neighbours (Pakistan, Bangladesh, Nepal and Sri Lanka), providing a comprehensive description of a wide range of topics, from extreme weather events to the environmental impact of climate change. It is generally well written, although unfortunately the authors had not updated much of the material to include the most recent observations. For those seeking an understanding of the physical mechanisms involved in the climatology of South Asia, its weather systems and its year-to-year variability, this book provides little in the way of answers. That said, it is a valuable teaching aid, is likely to appeal to the more casual reader and is an excellent reference book for dipping into.

Julia Slingo is at the Centre for Global Atmospheric Modelling, University of Reading, Earley Gate,

Reading RG6 6BB, UK.

\section{Related books}

Antarctic Meteorology and Climatology by J. C. King and J. Turner. CUP, £55, \$90.

El Niño Southern Oscillation and Climatic Variability edited by R. Allan, J. Lindesay and D. Parker. CSIRO, \$110.

The Weather of Britain by Rob Stirling.

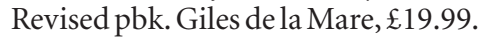

Watching the Weather by John and Mary Gribbin. Constable, $\mathfrak{E} 7.95$ (pbk).

The Weather Book: An Easy-to-Understand Guide to the USA's Weather by Jack Williams. Revised pbk. Vintage, \$20. 